\title{
ALGORITMOS: códigos invisíveis (d)e injustiça
}

\author{
Cristhian Magnus de Marco ${ }^{1}$ \\ Mariana Carolina Lemes ${ }^{2}$ \\ Daniel Roxo de Paula Chiesse ${ }^{3}$
}

Resumo: Os algoritmos servem para a discussão da opressão digital, permitindo inquirir como algoritmos tendenciosos viabilizam a perpetuação da desigualdade e novas formas de perfilamento racial. Novas tecnologias - algoritmos digitais, em especial - influenciam as percepções e impressões subjetivas e reacendem estereótipos sociais, prejudicando conquistas da segunda dimensão dos direitos fundamentais. É objetivo demonstrar a influência dos algoritmos na sociedade digital. A utilização dos algoritmos para justificação e fortalecimento de relações de poder que vão de encontro com os valores da igualdade. $\mathrm{O}$ estudo multidisciplinar segue o procedimento monográfico; técnica de pesquisa baseada na revisão bibliográfica, com aplicação do método hipotético-dedutivo.

Palavras-chave: Algoritmos; Desigualdade social; Discriminação positiva; Estereótipos; Injustiça.

\section{ALGORITHMS: invisible codes of unfairness}

Abstract: Algorithms serve to discuss digital oppression, allowing us to inquire how biased algorithms enable the perpetuation of inequality and new forms of racial profiling. New technologies - digital algorithms, in particular - influence subjective perceptions and impressions and rekindle social stereotypes, undermining achievements of the second dimension of fundamental rights. It aims to demonstrate the influence of algorithms on the digital society. The use of algorithms for justification and strengthening of power relations that meet the values of equality. The multidisciplinary study follows the monographic procedure; research technique based on bibliographic review, with application of the hypothetical-deductive method.

Keywords: Algorithms; Social inequality; Positive discrimination; Stereotypes; Injustice.

\section{Introdução}

Tomando por tema os algoritmos e, delimitando o espectro da pesquisa à opressão digital entre grupos específicos, já marginalizados anteriormente, através do uso e manipulação de tecnologias e conteúdos digitais na internet, o trabalho se propõe responder como algoritmos tendenciosos podem viabilizar a perpetuação da desigualdade, permitindo, ainda, novas formas de perfilamento racial ao assumir estereótipos sociais combatidos historicamente. Visa-se,

\footnotetext{
${ }^{1}$ Doutor em Direito pela Pontifícia Universidade Católica do Rio Grande do Sul - PUC/RS. Pós-doutorado e Mestrado em Direito pela Universidade Federal de Santa Catarina - UFSC. Professor e Pesquisador do Programa de Pós-graduação em Direito (Mestrado e Doutorado) da Universidade do Oeste de Santa Catarina - UNOESC. email: cristhian.demarco@unoesc.edu.br.

${ }^{2}$ Doutoranda em Direito pelo Programa de Pós-Graduação (stricto sensu) em Direitos Fundamentais, Universidade do Oeste de Santa Catarina, UNOESC. Mestre em Direitos Sociais, Difusos e Coletivos, Centro Universitário Salesiano, UNISAL. Professora do Curso de Bacharelado em Direito da UNOESC - campus Chapecó. Advogada. e-mail: mariana.lemes@unoesc.edu.br.

${ }^{3}$ Mestre em Direitos Sociais, Difusos e Coletivos, Centro Universitário Salesiano, UNISAL. Professor do Curso de Direito da Fundação Educacional Rosemar Pimentel - campus Volta Redonda. Coordenador e Professor do Curso de Pós Graduação em Direito Civil e Processual Civil da Fundação Educacional Rosemar Pimentel - campus Volta Redonda. Advogado.e-mail: daniel@chiesse.adv.br.
}

Rev. de Direito, Inovação, Propriedade Intelectual e Concorrência | e-ISSN: 2526-0014 | Evento Virtual| v. 6 | n. 1 | p. 1-17 | Jan/Jun. 2020 
como o próprio título antecipa, demonstrar que os algoritmos marcados por preconceitos e estereótipos que reforçam assimetrias sociais e injustiças.

Justifica-se a escolha do presente tema por ser o ideário de justiça uma preocupação com os retornos relativos entre si e os outros ou entre terceiros, melhor compreendido a partir da aversão à desigualdade. A confiabilidade de percepções e impressões subjetivas em tempos digitais requer a reflexão filosófica do diagnóstico de injustiça, de modo a reafirmar a necessidade de exame crítico para a validação dessa conclusão. Essa constatação permite apresentar como a exploração da revolução digital promovida nas últimas décadas para a obtenção de dados pessoais massivos dos indivíduos (big data) e seu emprego destinado à manipulação de votos, compras ou preferências e opiniões pessoais dos usuários determina a necessidade de uma análise da democracia e, das teorias da justiça, no que respeita à percepção da injustiça. A premissa assumida, recorrendo à ideia de Safiya Umoja Noble, é de que a forma de emprego dos algoritmos nos ambientes digitais levam ao racismo, sexismo e demais práticas de opressão, uma vez que reafirmam relações de injustiça anteriores entre grupos já marginalizados, através do uso de tecnologias e conteúdos digitais na internet, causando, ainda, políticas e práticas deturpadas.

A hipótese inicial é de que as novas tecnologias - e, em especial os algoritmos digitais - influenciam as percepções e impressões subjetivas do "eu digital" e, reacendem estereótipos sociais, prejudicando conquistas da segunda dimensão dos direitos fundamentais.

Com esse objetivo, pretende-se demonstrar a influência dos algoritmos na sociedade digital. Apresentam-se como objetivos específicos apresentar discutir o processo de tomada de decisões justas; evidenciar como os algoritmos podem ser utilizados para manipular a opinião dos usuários; problematizar a criação e extração de interpretação algorítmicas tendenciosas.

Apresenta-se como tese a utilização dos algoritmos para justificação e fortalecimento de relações de poder que vão de encontro com os valores da igualdade ao promover a propagação do subjetivismo racista, sexista e preconceituoso.

Trata-se de estudo multidisciplinar que segue o procedimento monográfico, fazendo uso da técnica de pesquisa baseada na revisão bibliográfica, com aplicação do método hipotético-dedutivo, com a exploração da literatura sobre sistemas de aprendizado de máquinas justas e algoritmos racistas e preconceituosos. Com essas considerações, propõe-se a desenvolver o tema de modo a permitir uma visão plausível sobre o problema. 
Conclui-se que no atual estado da arte, os algoritmos reproduzem conceitos ou imagens preconcebidas, padronizadas e generalizadas estabelecidas pelo senso comum de uma sociedade que ainda não alcançou internalizou os direitos de igualdade e, ainda tem suas percepções e impressões subjetivas influenciadas por algoritmos que expressam relações de poder contaminadas por injustiças claras, a demandar a busca por um futuro em que os algoritmos sejam mais éticos.

\section{Aversão à injustiça, verdade e subjetivismo na era digital}

Um componente-chave do senso humano de justiça é a aversão à desigualdade, definida como a disposição de sacrificar os ganhos materiais e pessoais em prol de uma maior igualdade.

Não se espera que o mundo seja perfeitamente justo. Injustiças claras, porém, devem ser removidas, corrigidas; as percepções e impressões de cada indivíduo, porém, estão cada vez mais baseadas em notícias falsas, preconceitos e impressões pessoais influenciadas ou manipuladas pelo poder dos algoritmos, dificultando o processo de depuração e mesmo a percepção de justiça.

Meticulosa e perceptiva análise histórica conduzida por Barrington Moore Jr. (apud Bauman, 1998) evidenciou que as massas têm uma ideia vaga - ou ideia nenhuma - da noção abstrata de justiça como tal, mas tendem ao reconhecimento infalível de uma injustiça: "em oposição ao que a lógica do vocabulário sugere, "injustiça" é a noção positiva, enquanto "justiça" é a negativa". O sentido de justiça é compreendido a partir da compreensão da injustiça, servindo para a correção da distorção identificada. A percepção popular de injustiça tende a expandir-se de acordo com a intensificação das práticas já condenadas como injustas e surgimento de novas situações assim catalogadas. A maior percepção e condenação das injustiças nas últimas décadas - marcadamente a partir da década de 1960 - aparece associada ao aumento da alfabetização e da expectativa de vida, sendo que a expansão da comunicação mundial permitiu, também, o maior e melhor reconhecimento de injustiças, na medida em torna evidente a comparação entre padrões de vida desiguais. (MOORE JR, apud BAUMAN, 1998).

Sampedro (2015) questiona ${ }^{4}$, se o senso de justiça está na natureza humana, ou é um produto sociocultural. Para ele, uma parte do senso de justiça se desenvolve espontaneamente

\footnotetext{
${ }^{4}$ As colocações de Sampedro (loc. cit.) estão baseadas em pesquisas realizadas pelos psicólogos e antropólogos Peter Blake, da Universidade de Boston; Katherine McAuliffe, de Yale e Harvard, e seus colegas de Salk Lake 
nas crianças de quatro anos de qualquer sociedade, enquanto outro componente só aparece aos oito anos e depende drasticamente do ambiente cultural, desenvolvendo-se melhor nas crianças ocidentais que nas de países em desenvolvimento. O parâmetro chave para a condução do estudo, muito consolidado na psicologia experimental, chama-se "aversão à injustiça" (inequity aversion), mensurado através de dois experimentos: "aversão à injustiça em desvantagem" e, "aversão à injustiça em vantagem" ${ }^{5}$, sendo que este último nível de identificação de injustiças implica um sacrifício imediato maior, que, pelo que sabem os evolucionistas, parece ser uma característica exclusivamente humana. (BLAKE et. al., 2015).

Comportamentos abstratos como equidade e aversão à injustiças podem influenciar o comportamento humano. Estudos da literatura sobre preferências sociais apontam que a maior parte dos indivíduos se comporta de maneira interessada em algumas circunstâncias, enquanto em outras, uma grande maioria se comporta como se estivesse fortemente preocupada com a realização de justiça. (FEHR; NAEF; SCHMIDT, 2006). Dirk Engelmann e Martin Strobel, em estudo de 2004, questionaram, porém, a relevância da aversão à injustiça e, alegaram que a combinação da eficiência e da regra de Maximin de Rawls para ajudar os menos favorecidos é mais importante. (ENGELMANN, DIRK, 2004 apud FEHR; NAEF; SCHMIDT, 2006). Segundo a regra de Maximin rawlsiana, deve-se identificar o pior resultado de cada alternativa disponível e então adotar a alternativa cujo o pior resultado é melhor do que os piores resultados de outras alternativas (Rawls, 2003, p. 137). A regra não foi proposta como princípio geral de decisão racional nos casos de risco e incerteza; considerando-se as perspectivas de uma posição original, a regra de Maximin serviria para a descoberta útil à organização das escolhas. $\mathrm{O}$ experimento de Fehr, Naef e Schmidt evidenciou, porém, que entre economistas, a maior parte prefere escolhas eficientes, ainda que delas advenham injustiças, enquanto entre os nãoeconomistas, a maior parte preferente escolhas baseadas no senso de justiça e equidade. Não foram verificadas interferências dos ideários políticos do sujeitos pesquisados nos resultados apontados, contudo, verificou-se que mulheres favorecem mais a equidade em suas escolhas do que os homens.

City, Columbia Britânica e Nova Escócia, no Canadá, e Dakar Fann, no Senegal, na qual foram analisadas 1.732 crianças de 4 a 15 anos de idade do Canadá, Índia, México, Peru, Senegal, Uganda e Estados Unidos.

${ }^{5} \mathrm{O}$ primeiro visa identificar a "aversão à injustiça em desvantagem" em crianças de 4 anos dos países investigados; o intuito é identificar e refutar injustiças que implicam um custo imediato mas contribuem com benefícios a longo prazo, denunciando a intolerância a abusos similares e ganhos de benefícios excessivos. Segundo os condutores da pesquisa, essa é uma característica que compartilhamos com primatas não humanos e outras espécies sociais. O grau superior de aversão à injustiça - aparentemente altruísta - só se desenvolveria por volta dos 8 anos de idade, e sobretudo nas sociedades ocidentais, sendo medido pelo experimento de "aversão à injustiça em vantagem", podendo ser avaliado num segundo ensaio.

Rev. de Direito, Inovação, Propriedade Intelectual e Concorrência | e-ISSN: 2526-0014 | Evento Virtual| v. 6 | n. 1 | p. 1-17 | Jan/Jun. 2020 
Como aponta Sen (2009), o senso de injustiça não deve basear-se apenas em percepções e impressões subjetivas, mas, sim, envolver o uso da razão, baseando-se num exame crítico, cuidadoso, da validade desta conclusão; as injustiças estão inevitavelmente presentes, sendo imprescindível a "percepção firme de injustiças manifestas". A ausência de uma justiça completa não deve isentar a sociedade de expugnar as desigualdades remediáveis. Aliás, as injustiças corrigíveis seriam, para o autor, a própria mola propulsora das teorizações da justiça.

Assim apresentada a questão pertinente à aversão à injustiça, cabe investigar como o meio ambiente e as tecnologias digitais podem influenciar a noção de verdade e, contaminar as decisões dos indivíduos, diminuindo a confiabilidade do subjetivismo através do 'technological redlining ${ }^{6}$ e, majorando o perfilamento social ${ }^{7}$.

Para Oliveira (2018), a verdade é considerada por alguns como sendo apenas uma grife no "mercado de ideias", uma arma na disputa por poder. Em tempos de pós-verdade, as pessoas são conduzidas, manipuladas, a identificar, compreender e aceitar apenas aquilo que o mercado de tecnologia de informação e comunicação (TIC) assim rotule. (PUCPR, 2018).

À necessidade de leitura do que se sente e aparentemente se vê segue-se o questionamento sobre o que essas percepções indicam e como podem ser levadas em conta. (SEN, 2011). A confiabilidade do subjetivismo serve como um sinal, mas exige que se conduza um exame cuidadoso da validade dessas conclusões: compreender o mundo envolve o uso da razão, não se tratando apenas de um registro das percepções pessoais imediatas.

Sen (SEN, 2011) questiona, ainda, sobre quais tipos de argumentação racional devem contar na avaliação de conceitos éticos e políticos como justiça e injustiça, reforçando a imperiosidade de imparcialidade em algum sentido específico, culminando por problematizar o papel da racionalidade e razoabilidade na compreensão das exigências da justiça.

Em tempos de pós-verdade, de aceleração do fenômeno das fake news e utilização massiva de algoritmos, a verdade se torna uma palavra plurívoca; todos e cada um se consideram proprietários dos fatos e, avalizados à sua interpretação. Neste contexto, cada vez mais injustiças são denunciadas. Dessas, algumas podem ser racionalmente comprovadas, enquanto outras baseiam-se em dados e notícias falsas, que buscam levar o público e a

\footnotetext{
${ }^{6}$ Safyia Umoja Noble introduz a terminologia 'technological redling' em sua obra 'Algoritmos da Opressão' querendo, por ela indicar as práticas de criação e perpetuação de injustiças entre grupos anteriormente já marginalizados através do uso de tecnologias digitais, conteúdos e internet, bem como injustiças causadas por políticas e práticas de tecnologias digitais. (NOBLE, 2018).

${ }^{7}$ Perfilamento racial (Racial profiling ou, ainda, ethnic profiling) é o ato de suspeitar ou visar uma pessoa de uma determinada raça, etnia, religião ou nacionalidade, com base em características ou comportamentos observados ou assumidos de um grupo racial ou étnico. (WARREN; FARRELL, 2009).
} 
sociedade a perpetuar e reavivar preconceitos, reforçando estereótipos. (SALAS, 2017; PASCUAL, 2019).

A teoria da justiça apresentada por Sen (SEN, 2011), por seu sentido bem amplo, mostra-se adequada para esclarecer como enfrentar o problema do diagnóstico de injustiças na sociedade da informação. Isso porque, ela se diferencia claramente das teorias da justiça predominantes na filosofia moral e política contemporâneas. Explica-se: a teoria da justiça de Sen inclui modos de julgar como reduzir injustiças e promover a justiça, permitindo a tomada de decisões sobre as instituições, o comportamento e outros determinantes da justiça. $\mathrm{O}$ autor considera a pluralidade valorativa, embasando-se em estudo de Isaiah Berlin e Bernard Willians para identificar que as pluralidades podem sobreviver dentro de dada comunidade, ou mesmo para uma pessoa específica. As experiências e tradições de cada um podem levar à produção de argumentos razoáveis em direções conflitantes.

Refratário àquela que denomina "tolerância descomprometida", Sen (2011) conclama que a argumentação fundamentada e não a aceitação preguiçosa deve servir para o exame crítico e análise imparcial de questões atinentes à justiça e, ressalta que a presença de uma injustiça remediável pode, em grande medida, estar conectada a transgressões de comportamento, e não a defeitos institucionais. Para Sen, "a argumentação racional é central para a compreensão da justiça em um mundo que inclui muita 'desrazão'; na verdade, ela pode ser especialmente importante em um mundo assim." (SEN, 2011, p. 21). Deste modo, importa levar mais e mais argumentação racional às questões de justiça, oferecendo soluções para questões práticas imediatas - como estas da era digital -, aceitando fundamentações plurais aptas a definir a visão do enfoque das capacidades, cuja incompletude poderia encontrar solução na discussão pública, vez que "cabe a cada sociedade, através da argumentação racional pública, definir uma lista de capacidades mínimas a serem garantidas, com seus devidos pesos, para então reduzir ao máximo as desigualdades de capacidades sobreviventes." (COUGO, 2016, p. 158-159).

Como informado por Sen (2011), existem diversas formas de medir o sucesso de uma sociedade e, esta é muito mais justa e desenvolvida na medida puder prover aos indivíduos a fruição de um conjunto de direitos invioláveis. Ocorre que, enquanto alguns priorizam direitos e liberdades negativas, deixando em um segundo plano questões como as desigualdades, outros preferem a satisfação de desejos em prejuízo das liberdades individuais. Assim, após rejeitar as teorias utilitaristas, libertárias e do liberalismo político, Sen propõe o 'enfoque das capacidades', considerando o ser humano como dotado de reais possibilidades, respeitado como agente e, não

Rev. de Direito, Inovação, Propriedade Intelectual e Concorrência | e-ISSN: 2526-0014 | Evento Virtual| v. 6 | n. 1 | p. 1-17 | Jan/Jun. 2020 
mero joguete das ações governamentais. (SEN, 2000). Não é livre o indivíduo manipulado, aquele que serve de mofa; não são livres, igualmente, aqueles dominados pela verdade algoritmizada.

\section{3 "Verdade" algoritmizada}

Os algoritmos digitais, introduzidos como ferramentas para aprimorar a experiência das pessoas e oferecer o que cada usuário busca baseado nos dados produzidos massivamente pela sociedade (big data), ao invés de facilitar a experiência pessoal, passaram a ser utilizados desde logo como valor agregado por gigantes como Google, Apple, Facebook e Amazon (GAFA) para atrair os consumidores por meio de notícias e anúncios, produzindo linhas desconhecidas de algoritmos cuja legalidade das decisões só pode ser verificada por quem tem a base de dados, a sequência de ações e conhece e entende a ponderação dos critérios de decisão, o que Martini (2018) denomina de "modo matemático-lógico de resolução de problemas". Ao analisar o mesmo fenômeno, não do ponto de vista rentabilista, mas, sim, dos direitos dos usuários e evolução social, Noble (2018) os chama "algoritmos da opressão" e, O'Neil (2017), de "instrumentos matemáticos de destruição". As evidências depõe para o fato de que a sociedade de informação utiliza seus usuários como matéria-prima, realizando o consumo virtual destes e, transformando as informações decodificadas em lucro (LOBE, 2018).

Rosal (2018, pp. 69-75) aponta seis atributos principais observáveis em qualquer análise de algoritmos (ubiquidade ${ }^{8}$, opacidade ${ }^{9}$, complexidade $^{10}$, valores integrados ${ }^{11}$, capacidade de criar a realidade e perpetuar condições ${ }^{12}$ e, a possibilidade de serem sujeito a gaming $^{13}$ ), que justificam concluir que "verdade" na era digital é um produto algoritmizado. No dizer de Köves (2004, p. 60), "a ideia pós-moderna da "verdade como relativa" autoriza

\footnotetext{
${ }^{8}$ Possibilidade de mediar o conhecimento humano assumidos, notadamente em mecanismos de busca, redes sociais e páginas principais de portais. (ROSAL, 2018).

${ }^{9}$ Os dados são coletados sem que haja informação transparente a respeito do emprego futuro dos dados, ou mesmo ciência da sua coleta ou resultados obtidos. Para que a informação seja transparente, não basta que seja prestada de modo técnico e complexo e, portanto, ininteligível ao público. (ROSAL, 2018).

10 Muitas vezes os algoritmos são apresentados de forma complexa, imprimindo o medo da matemática, escondendo atrás de suas fórmulas a alegada complexidade, de modo a desencorajar a busca por sua compreensão. (O'NEIL, 2017).

${ }^{11}$ Os algoritmos são submetidos a valores integrados que estão encobertos pela codificação e que visam o aumento contínuo do sucesso e do lucro. (O'NEIL, 2017; ROSAL, 2018).

12 Os algoritmos moldam e são moldados pelos valores sociais, retroalimentando preconceitos (feedback loops), por exemplo. (O'NEIL, 2017; ROSAL, 2018).

${ }^{13}$ Trata-se da fraude encoberta pelos algoritmos, ou seja, os modos empregados para influenciar os resultados de pesquisas, impulsionando, por exemplo, alguns conteúdos, ou, modificação na programação de um site para que este obtenha melhor classificação nos mecanismos de busca. (ROSAL, 2018).
} 
comentadores, repórteres e jornalistas a tratar fatos e história de modo casual", desempenhando a mídia um papel subversivo, como diversas notícias podem demonstrar.

Adaptativos e performativos, os algoritmos produzem alterações nos espaços de convivência social e nas pessoas sem que sejam percebidos, moldando comportamentos e escolhas políticas, motivo pelo qual não podem ser considerados simples e, muito menos neutros. (SILVEIRA, 2019).

O nó górdio da problemática pertinente à verdade na sociedade da informação reside na procedência das informações, não se podendo descuidar da origem das suas informações, identificação e repressão de notícias falsas. Embora a demanda por mais transparência seja crescente, está baseada na ideia de que os algoritmos precisam apenas ser divulgados para que sejam controlados democraticamente, o que talvez não garanta o sucesso e resultados que se almeja. (LOBE, 2018).

Fatos e preferências podem ser emoldurados, moldados ou mesmo distorcidos, impactando modos de vida sem que as pessoas sequer se deem conta, comprometendo, inclusive, o diagnóstico de injustiças e, fortalecendo o racismo, como denuncia Noble (2018). Cada vez mais, os sistemas autônomos e seu processo de tomada de decisão são objeto de atenção e regulamentação social, traduzindo-se em fonte de preocupação para juristas e cientistas, preocupados com a sua opacidade e com o direito à explicação (right to explanation $^{14}$ ) e a segurança das informações do "eu digital". (CANOTILHO, 2019).

Dados algoritmizados podem prever e até mesmo modificar comportamentos (ARVANITAKIS, 2017). A inteligência artificial se utiliza da sociedade, aproveitando-se da pessoa de seus indivíduos, para estabelecer controle emocional. (RAINIE; ANDERSON; ALBRIGHT, 2017). Notícias manipulam nossos votos, valores e conduta moral através de

\footnotetext{
${ }^{14}$ O Regulamento Geral de Proteção de Dados da União Europeia (2018) teve impactos potenciais no uso rotineiro de algoritmos de aprendizado de máquina ao colocar restrições à tomada de decisão individual automatizada (ou seja, algoritmos que tomam decisões com base em preditores no nível do usuário) que "afetam significativamente" os usuários. A lei também gerou um direito à explicação, pelo qual um usuário pode pedir uma explicação de uma decisão algorítmica que o afeta significativamente, demandando estruturas de avaliação que evitem a discriminação e permitam explicações. Por sua importância, foi denominada como a "Revolução de Copérnico" em leis de processamento de dados. (GOODMAN, FLAXMAN, 2017, tradução dos autores).
} 
empresas especializadas, transformando as fake news ${ }^{15}$ e o crowdsourcing $^{16}$ num negócio sujo rentável, ilegal e anônimo. (AZEVEDO, 2018).

Para alcançar sua finalidade, as fake news se utilizam, basicamente, de cinco elementos (título de isca ${ }^{17}$, conteúdo de pré-visualização ${ }^{18}$, a segmentação ${ }^{19}$, a utilização de ferramentas legítimas ou não ${ }^{20}, \mathrm{e}$, a plataforma de publicação ${ }^{21}$ ) que dão suporte à motivação velada de seu conteúdo $^{22}$, fazendo com que ela prospere, seja porque as pessoas são condicionadas a acreditar, ou porque todos têm seu conjunto de inclinações (viés de confirmação) e querem participar, ou, pelo desejo de propagar conscientemente as notícias falsas. (AZEVEDO, 2018).

O "ciclo da opinião pública" ilustra como os instigadores das campanhas por de manipulação atingem seus objetivos quando se trata de mudar a opinião do público e combinálas com as das notícias falsas. O ciclo envolve sete fases (reconhecimento, armamento, entrega, exploração, persistência, manutenção, ações sobre o objeto e reforço) que, de modo resumido, destinam-se a definir os objetivos, estabelecer o público-alvo e entender como este percebe os acontecimentos ao seu redor e eventos históricos, considerando os fatos e, visando influenciar seu alvo a partir de "ameaças" a seu bem-estar e saúde própria ou da família. De posse desses

15 Fake news (numa tradução literal "notícias falsas"), também chamadas "guerra de informação", "hacking cognitivo", "propaganda cibernética" ou "campanhas de desinformação", é um termo extensivamente utilizado para denominar desde especulações a opiniões divergentes, teorias da conspiração, notícias, erros e desinformação que opera pela criação de notícias falsas, pela remoção de conteúdo legítimo (hacking), ou, ainda, pelo conceito de one-stop-shop (serviço completo), oferecendo uma gama de serviços que atende todas as demandas do cliente. Desde o reconhecimento de sua existência em 2016; de informações distorcidas até a publicidade paga no Facebook, o mercado das fake news denunciava pagamentos de até mil euros por dia por ocasião das eleições de Donald Trump. Após o escândalo da Cambridge Analytica e, repreensão do Facebook por não informar a seus usuários que seus dados foram utilizados, o negócio das notícias falsas desnudou um nicho com altos lucros, RPs habilidosas, inteligência artificial e engenheiros de big data, profissionais altamente qualificados e serviços oferecidos a influenciadores com grandes orçamentos. (AZEVEDO, 2018).

${ }^{16}$ Através desta prática são oferecidos incentivos aos usuários que ajudarem a espalhar a 'notícia'. (AZEVEDO, 2018).

17 Os títulos devem ser chamativos, atraentes, capazes de repercutir de forma exponencial. Azevedo menciona o poder que conteúdos partidários têm de amplificar uma notícia política falsa. (AZEVEDO, 2018).

${ }^{18}$ Secundário em relação ao título, mas, ainda assim importante, especialmente em plataformas como o Facebook, em que um campo com a descrição do post está disponível mesmo em links compartilhados, fornecendo a essência da fake news e, diminuindo o nível de crítica dos consumidores. (AZEVEDO, 2018).

19 A fake news pode visar uma fração específica da população, envolvendo aqueles com sentimentos favoráveis ou contrários a determinado tópico, pessoa ou lugar, ou destinar-se a causar confusão em massa, pode incluir pagamentos por um conteúdo para maior publicidade (exemplo disso são os 'impulsionadores de conteúdo') junto a um público específico. AZEVEDO, 2018).

${ }^{20}$ São diversas as ferramentas utilizadas para que o cliente permaneça anônimo e, distanciados da prática de atos que possam ser eticamente questionáveis. (AZEVEDO, 2018).

${ }^{21}$ Algumas plataformas têm algoritmos que detectam histórias consideradas como spam, impróprias ou ofensivas, mas seus algoritmos podem ser ignorados por bots; os mecanismos aptos a apoiar a proliferação de fake news aprender como burlar sistemas de controle. (AZEVEDO, 2018).

22 Para Azevedo, os quatro motivadores principais das fake news são a difamação de caráter, o lucro, propósitos políticos e satisfação pessoal. (AZEVEDO, 2018).

Rev. de Direito, Inovação, Propriedade Intelectual e Concorrência | e-ISSN: 2526-0014 | Evento Virtual| v. 6 | n. 1 | p. 1-17 | Jan/Jun. 2020 
delineamentos, o instigador passa a utilizar as notícias falsas como armas; quanto mais notícias com o mesmo conteúdo, mais popular ela se torna. Para inserir sua campanha, o instigador pode buscar desestabilizar sistemas de crenças atuais do seu público, fazendo com que sejam questionadas construções cognitivas existentes para, então, centralizar sua campanha de manipulação. A partir daí, o instigador utiliza a pressão social, o efeito manada e o medo da alienação social para persuadir indivíduos ou grupos, podendo se beneficiar de autoridades respeitadas pelo indivíduo-alvo. Os resultados de uma campanha de manipulação são maximizados com a maior visibilidade da notícia, através de várias plataformas, chamadas e aumento de circulação. Com a manutenção da campanha, ideias que inicialmente pudessem ser tidas como impensáveis passam, com o tempo, a serem consideradas como radicais, aceitáveis, sensatas, convertendo-se em populares e políticas ${ }^{23}$, conforme explica Azevedo (2018).

Com o aprendizado da política e o processo de decisão cooptados, os dados produzidos pela sociedade de massa é objeto de análise e manipulação, corrompendo o sistema democrático a partir de seu componente subjetivo e, afetando a justiça, constatação flagrante de que a democracia não está preparada para as inovações trazidas pelos algoritmos. Não há argumentação racional; a escalada de comportamentos não civilizados e manipulativos baseados em fake news, preconceitos albergados e demais subjetivismos exacerbados pelos ambientes virtuais demonstram inequívocos prejuízos para a troca aberta de ideias e a identificação de injustiças, empobrecendo o diagnóstico popular destas e, ensejando práticas e perpetuações de injustiças.

\section{Algoritmos tendenciosos e relações de poder}

Os sistemas de aprendizado de máquina atuam cada vez mais em todas as facetas da vida em sociedade, seja na saúde e educação ou em notícias e postagens de mídia social, em entrevistas de emprego e, ainda, na predição da recidiva de crimes ou alocação de aumento de contingente policial.

Com o crescimento de sua utilização, o potencial dos algoritmos para ampliar as desigualdades sociais e injustiças vem ensejando pesquisas sobre comportamentos sistêmicos

\footnotetext{
${ }^{23}$ Trata-se da 'janela de overton', também conhecida como 'janela do discurso', termo derivado de seu criador, Joseph P. Overton, ex-vice-presidente do Centro de Políticas Públicas de Mackinac, no Michigan, Estados Unidos, que, em sua descrição da janela, afirmou que a viabilidade política de uma ideia depende principalmente dela cair dentro da janela, ao invés das preferências individuais dos políticos. Sua janela inclui uma gama de políticas consideradas politicamente aceitáveis no clima atual da opinião pública, que um político pode recomendar sem ser considerado excessivamente extremo para obter ou manter cargos públicos. (LEHMAN, 2010).
} 
injustos observados em sistemas de aprendizado de máquinas amplamente utilizados (os diversos exemplos citados pela literatura vão desde a preferência por candidatos de um determinado gênero para vagas de emprego ou promoções até resultados racistas e sexistas em ferramentas de pesquisa da internet ${ }^{24}$ ). Por afetar a vida de milhões de usuários, a busca de ferramentas justas de sistemas de aprendizados de máquinas vem dando azo a esforços destinados ao desenvolvimento de definições estatística de justiça e métodos algorítmicos para avaliar e mitigar vieses indesejáveis em relação a essas definições. (HOLSTEIN et. al., 2019²5). Como os algoritmos reproduzem tendências preconceituosas e injustas manifestadas pelo público junto ao qual são coletados os dados, uma das implicações do trabalho de Holstein et. al. (2019) é a de que futuras pesquisas devem explorar maneiras de melhor compreender os dados e mitigar esses vieses, concluindo que a pesquisa sobre aprendizado de máquinas justas raramente é guiado por uma compreensão dos desafios enfrentados pelos profissionais ${ }^{26}$. Após a pesquisa exploratória respeitante à "distorção" algorítmica, pesquisas futuras devem subsidiar investigações sobre coleta e curadoria de conjuntos de dados de alta qualidade com consciência da justiça, bem como recursos educacionais, métricas, processos e ferramentas específicos para a compreensão da justiça em diferentes contextos e aplicações, com o desenvolvimento de processos e ferramentas para depuração focada na justiça e auditorias automatizadas.

A pesquisa de Holstein et. al. (2019), ao manifestar-se quanto às injustiças decorrentes da aplicação de modelos algorítmicos sob a perspectiva dos profissionais da área de aprendizado de máquinas, assim consignou que os preconceitos e injustiças seriam "problemas

${ }^{24}$ HOLSTEIN et. al., 2009; O'NEIL, 2017.

25 Trata-se da primeira investigação sistemática dos desafios e necessidades dos profissionais da área de aprendizado de máquinas em relação à justiça. Através foi possível identificar, por exemplo, que a maioria dos profissionais de mercado entrevistados consideravam a coleta de dados mais importante que o próprio modelo de processamento das informações. Ademais, a literatura de aprendizado de justiça por sistemas de aprendizado de máquinas tende a focar em domínios onde a justiça possa ser objetivamente compreendida a partir de métricas quantitativas bem definidas, enquanto os profissionais demandam métodos mais holísticos de auditoria no nível do sistema e, demandaram a importância de considerar-se vieses e "pontos cegos" nos humanos que participam da segmentação de instruções que permite que a CPU realize a busca de uma ou mais instruções além da próxima a ser executada (pipeline). Outra demanda compreendida pelo estudo é a preocupação com os "pontos cegos" das equipes de produtos, demandando a previsão de quais subpopulações e formas de injustiça precisam ser consideradas para tipos específicos de aplicativos de aprendizado de máquinas. (HOLSTEIN et. al., 2009).

${ }^{26}$ A pesquisa foi conduzida através de uma série de perguntas semiestruturadas, individuais, com um total de 35 profissionais, em 25 equipes de produtos de aprendizado de máquinas. Para investigar a prevalência e a generalidade dos principais temas que surgiram nessas entrevistas, foi realizada uma pesquisa anônima com uma amostra mais ampla de 267 praticando de aprendizado de máquinas da indústria. Tanto para as entrevistas quanto para a pesquisa os profissionais foram definidos amplamente como aqueles que trabalham em qualquer função de uma equipe que desenvolve produtos ou serviços que envolvem aprendizado de máquinas. $\mathrm{O}$ estudo passou por revisão ética e foi aprovado, com disponibilização das entrevistas e perguntas de pesquisa em material complementar. (HOLSTEIN et. al., 2009).

Rev. de Direito, Inovação, Propriedade Intelectual e Concorrência | e-ISSN: 2526-0014 | Evento Virtual| v. 6 | n. 1 | p. 1-17 | Jan/Jun. 2020 
fundamentalmente sócio-técnicos, e que os esforços de pesquisa com foco técnico devem acompanhar os esforços para melhorar os processos, políticas e educação organizacionais". Os pesquisadores apontam que a mídia normalmente se utiliza de um enquadramento de dentro para fora para se manifestar sobre o caráter tendencioso de algoritmos em sistemas de aprendizado de máquinas, enquanto a literatura sobre justiça destas ferramentas concentra-se predominantemente no desenvolvimento de métodos algorítmicos para atenuar vieses, visualizando o conjunto de dados como fixo, ou seja, atuando nos modelos de aprendizado de máquinas. Foram coletadas evidências de que os desenvolvedores de modelos e os coletores de dados necessitam de mais e melhores ferramentas para facilitar a compreensão de dados coletados, bem como a orientação ativa na coleta de dados à medida que ela ocorre, de modo a apoiar a justiça nos modelos de aprendizado de máquinas em seu nascedouro ${ }^{27}$ e, assim, imprimir mais justeza à sua interpretação, de modo a evitar resultados que causem um preconceito injusto ou contra pessoas ou grupos e coisas.

De Castro, Zona e Bocci (2020) descrevem que as sociedades capitalistas e pósindustriais baseadas em dualismos (e.g. masculino/feminino) refletem uma visão do mundo sujeito dominante (masculino, branco, capaz de trabalhar), cuja normalidade é definida por meio de parâmetros como heterossexualidade e produtividade individual, a qual contamina o design dos algoritmos (devido ao fato de serem estes expressos em linguagem matemática os algoritmos seriam dotados de neutralidade, mas nos últimos anos vários matemáticos ressaltam sua parcialidade e, descrevem que construções culturais afetam diretamente as respostas que ele fornece). Além disso, se o conjunto de dados no qual o algoritmo atua não contempla a

\footnotetext{
${ }^{27}$ Parte contundente do estudo demonstra que a coleta de dados pelos métodos algorítmicos desenvolvidos não é capaz de coletar dados de qualidade. Veja-se o exemplo a seguir, onde um dos pesquisados se manifesta no sentido da necessidade de obtenção de dados de qualidade sobre estudantes afro-americanos com pontuação alta, declarando que os dados coletados não costumam expressar tal realidade e questionando sobre as técnicas que poderiam ser utilizadas para esta coleta: "Por exemplo, em resposta à pergunta da entrevista "oracle", um engenheiro de ML (R19) trabalhando na pontuação automatizada de ensaios observou: "Para pontuar de maneira justa os estudantes afro-americanos, eles precisam de exemplos de estudantes afro-americanos com uma pontuação alta. Mas nos dados [a equipe de coleta de dados] coleta [s], isso é muito raro. Então, qual é o caminho certo para obter uma amostra dos [melhores marcadores] sem ter que marcar todos os ensaios? [...] Então [precisamos] de algum tipo de maneira ... para indicar [de quais escolas] coletar [...] ou o que se preocupar em gastar o dinheiro extra para pontuar". A maioria (60\%) dos participantes da pesquisa, dos $25 \%$ que indicaram que sua equipe tem algum controle sobre os processos de coleta de dados, indicou que ter essa orientação ativa seria pelo menos "Muito" útil. Por outro lado, em contextos em que os dados de treinamento são coletados por usuários regulares e "inativos" de um produto, podem surgir desafios quando populações especificas de usuários estão menos envolvidas com o produto. Para superar esses desafios, um gerente técnico que trabalha no reconhecimento de fala (R31) sugeriu que ajudaria a conhecer estratégias mais eficazes para incentivar o uso "in natura" de produtos em populações específicas, como técnicas de gamificação específicas." (HOLSTEIN et. al., 2019).
}

Rev. de Direito, Inovação, Propriedade Intelectual e Concorrência | e-ISSN: 2526-0014 | Evento Virtual| v. 6 | n. 1 | p. 1-17 | Jan/Jun. 2020 
heterogeneidade que caracteriza o espectro de diferenças (gênero, cultura, renda, entre outros), de modo que a máquina pode retornar visões de coisas marcadas por preconceitos e estereótipos que reforçam assimetrias sociais e injustiças ${ }^{28}$.

Wang et. al. (2020), por seu turno, enfoca o desenvolvimento de novas técnicas que atenuem os vieses algoritmos preconceituosos, defendendo que a inteligência artificial deve ser "tendenciosa" para evitar o reforço de estereótipos prejudiciais e, utiliza o que denomina "recomendador imparcial" para alcançar melhor justiça sem perder a precisão da previsão. $\mathrm{O}$ estudo concluiu, porém, que os usuários, em média, refletem estereótipos já impregnados na sociedade, o que causa implicações significativas no desenho e avaliação de algoritmos.

Informa Noble (2018) que a maior parte da atenção dada à proteção de informações on-line tem sido discutida legalmente como uma questão de "direitos", um tipo de propriedade, numa variedade de narrativas (e.g. "liberdade de expressão"), em que se ignora como a opressão algorítmica funciona e afeta a qualidade de vida. Para a autora, somente o fortalecimento e a expansão da democracia pode romper os grilhões de injustiças e impedir a opressão de segmentos raciais, religiosos e de gênero já marginalizados anteriormente.

Discutindo as pesquisas de Holstein et. al., De Castro, Zona e Bocci, Wang et. al. e Noble, pode-se deduzir que os algoritmos ressaltam preconceitos e desigualdades sociais da sociedade, motivo pelo qual medidas igualadoras devem ser introduzidas com urgência.

É insuficiente, porém, desejar que as informações sejam mais precisas e justas, embora certamente seja importante. Informações tendenciosas e materiais racistas e sexistas degeneram a teia social e, não podem ter circulação em contextos culturais de aceitabilidade.

\section{Conclusões}

\footnotetext{
${ }^{28}$ Baseados em Relatório de 2018, atribuem tal fato a empresas como Google e Apple, que preferem equipes de trabalho homogêneas, nas quais o padrão é representado pelo homem branco. Na empresa Google, $69,1 \%$ da equipe é formada por homens, sendo que 53,1\% se declaram brancos. Já na Apple, 50\% da equipe é de homens e, $67 \%$ da equipe se declara branca. Citam pesquisas que evidenciaram a ausência de neutralidade dos algoritmos, como a utilizada no estudo demonstrou uma correlação causal entre o gênero dos candidatos e a lucratividade do trabalho, com oferecimento de maior renda mensal a homens, concluindo pela existência de algoritmos tendenciosos, baseado em princípios sexistas de que os homens seriam mais adequados para ocupar determinadas posições de trabalho. Outra pesquisa se pauta na descoberta de que os algoritmos de reconhecimento facial da Microsoft, IBM e FACE++ confundem o gênero de mulheres com frequência muito maior do que a confusão existente entre homens brancos; todos os sistemas citados funcionam melhor com rostos masculinos e brancos. Esses softwares são utilizados para fins diversos, como inserção de publicidade personalizada nas redes sociais, contratações e empréstimos e, pela polícia, para fins preventivos, o que comprova que os erros são muito mais perniciosos a estes grupos já minoritários e vulneráveis como mulheres e afro-descendentes.
} 
A objetividade e precisão dos algoritmos representam uma das preocupações da sociedade atual. A administração de volumes de dados descomunais deve considerar direitos fundamentais como segurança e privacidade, sem descuidar, ainda, da autonomia no processo de tomada de decisões pelos cidadãos.

Em tempos de inteligência analítica voltados à Big Data, o processo decisório se transforma em verdadeiro mercado de análise de dados, servindo, indistintamente, a clientes ou usuários e, mesmo, a empresas e entidades, como instrumento de poder e mecanismo de manipulação social.

A sociedade da informação e, em especial, a era dos algoritmos deflagrou um processo de muito maior sujeição e submissão dos cidadãos, contribuindo para a derrocada da democracia - e, consequentemente, da deterioração da ideia de justiça - na medida em que se opõe e deteriora o processo emancipatório dos indivíduos.

Ofuscados, poucos indivíduos demonstram capacidade crítica para avaliar fatos difundidos diariamente na internet, enquanto as massas vêm servindo como instrumento para a difusão acrítica de mitos que atendem aos interesses de plutocratas em todo o mundo, corrompendo o diagnóstico popular de injustiças.

As pessoas acreditam nas fake news, fenômeno que pode ser atribuído a propensões cognitivas, ou seja, a padrões de julgamento irracionais derivados de inclinações pessoais, ideias preconcebidas, justificação e satisfação subjetiva, mas que vem sendo consciente e ilegalmente explorado por grandes corporações, autorizando e difundindo práticas de criação e perpetuação de desigualdades e injustiças, principalmente contra grupos já marginalizados. Outrossim, experiências com algoritmos tendenciosos e, a constatação de que os sistemas de aprendizado de máquina têm condições de criar e perpetuar desigualdades sociais e a injustiça, vem recrudescendo o interesse dos cidadãos e da academia na investigação sistemática dos desafios e suporte de equipes comerciais de produtos no desenvolvimento de sistemas mais justos e éticos, com o fortalecimento e a expansão da democracia e oposição à opressão de segmentos raciais, religiosos e de gênero já marginalizados anteriormente.

Indo ao encontro do pensamento de Noble, conclui-se pela necessidade de que o público recupere suas instituições e direcione seus recursos a serviço de uma democracia multirracial. 
Atualmente, os algoritmos ainda reproduzem conceitos ou imagens preconcebidas, padronizadas e generalizadas dos engenheiros dos sistemas de aprendizado de máquinas, dos profissionais desta área e, principalmente, de seus usuários.

Padrões de injustiças estabelecidas pelo senso comum de uma sociedade que ainda não alcançou internalizou os direitos de igualdade podem colocar em xeque conquistas históricas, máxime no que diz respeito a direitos de gênero e vedação ao racismo, demandando a busca por um futuro em que os algoritmos sejam mais éticos.

\section{Referências}

SEN, Amartya. A ideia de justiça. Tradução: Denise Bottmann, Ricardo Doninelli Mendes São Paulo: Companhia das Letras, 2011.

ARVANITAKIS, James. If Google and Facebook rely on opaque algorithms, what does that mean for democracy? Agosto, 2017. Disponível em: https://www.researchgate.net/publication/319163734. Acesso em: 09 fev. 2020.

BAUMAN, Zigmunt. O mal-estar da pós-modernidade. Rio de Janeiro: Zahar, 1998.

BLAKE, P. R. et. al. A ontogenia da justiça em sete sociedades. 18 nov. 2015. Disponível em: https://www.nature.com/articles/nature15703. Acesso em: 14 fev. 2020.

CANOTILHO, J. J. G. Sobre a indispensabilidade de uma Carta de Direitos Fundamentais Digitais da União Europeia. Revista do Tribunal Regional Federal da 1 Região, Brasília, DF, v. 31, n. 1, 2019. Disponível em: http://revista.trf1.jus.br/trf1/article/view/17/17. Acesso em: 08 abr. 2020.

COUGO, Felipe Ferreira. (2016). O enfoque das capacidades em Amartya Sen. Revista Enciclopédia de Filosofia. v. 5, p. 150-177. Disponível em: https://periodicos.ufpel.edu.br/ojs2/index.php/Enciclopedia/article/view/9349/6466. Acesso em: 09 abr. 2020.

DE CASTRO, Martina; ZONA, Umberto; BOCCI, Fabio. (2020). Gli algoritmi come construtti culturali. Una minaccia per l'inclusione scolastica e sociale. Disponível em: encurtador.com.br/ozDZ6. Acesso em: 11 abr. 2020.

FEHR, Ernst; NAEF, Michael; SCHMIDT, Klaus M. (2006). Inequality aversion, efficiency, and maximin preferences in simple distribution experiments: Comment. American Economic Review. Disponível em: https://pubs.aeaweb.org/doi/pdf/10.1257/aer.96.5.1912. Acesso em: 09 abr. 2020.

GOODMAN, Bryce; FLAXMAN, Seth. (2017). European Union Regulations on Algrithmic Decision Making and a "Right to Explanation". AI Magazine. v. 38, n. 3. Disponível em: https://doi.org/10.1609/aimag.v38i3.2741. Acesso em: 09 abr. 2020.

HOLSTEIN, Kenneth et. al. (2019). Improving Fairness in Machine Learning Systems: What Do Industry Practitioners Need?. In Proceedings of CHI Conference on Human Factors in

Rev. de Direito, Inovação, Propriedade Intelectual e Concorrência | e-ISSN: 2526-0014 | Evento Virtual| v. 6 | n. 1 | p. 1-17| Jan/Jun. 2020 
Computing Systems (CHI '19), May 4-9, 2019, Glasgow, Scotland UK. ACM, New York, NY, USA 16 Pages. Disponível em: https://doi.org/10.1145/3290605.3300830. Acesso em: 10 abr. 2020.

KÖVES, Margit. Fascism in the Age of Global Capitalism. Social Scientist, v. 32, n. 9/10 (Sep./Out., 2004), pp. 36-71. Disponível em: https://www.jstor.org/stable/3518207. Acesso em: 09 abr. 2020.

LEHMAN, Joseph G. An Introduction to the Overton Window of Political Possibility. Mackinac Center for Public Policy. April 8, 2010. Disponível em: https://www.mackinac.org/12481. Acesso em: 10 abr. 2020.

LOBE, Adrian. Wenn Programmierer mächtiger als Politiker werden. Süddeutsche Zeitung, 2018. Disponível em: https://www.sueddeutsche.de/digital/digitalisierung-unddemokratie-hey-mark-zuckerberg-meine-demokratie-ist-nicht-dein-labor-1.4049824. Acesso em: 08 fev. 2020.

MARTINI, Mario. (2018). Algorithmen als Herausforderung für die Rechtsordnung. Deutsches Forschungsinstitut für öffentliche Verwaltung. Disponível em: https://www.bmjv.de/SharedDocs/Downloads/DE/Praesentationen/SID18_Martini.pdf?_blob =publicationFile \&v=2. Acesso em: 09 fev. 2020.

NOBLE, Safiya Umoja. Algorithms of Opression: how search engines reinforce racism. New York: New York University Press, 2018.

OLIVEIRA, Marcos Barbosa. Pós-verdade: filha do relativismo científico? 15 jan. 2018. Disponível em: https://outraspalavras.net/tecnologiaemdisputa/pos-verdade-uma-filha-dorelativismo-cientifico/. Acesso em: 13 fev. 2020.

O'NEIL, Cathy. (2017). The era of blind faith in Big Data must end. Palestra proferida no evento TED2017. Vancouver. Disponível em: https://www.ted.com/talks/cathy_o_neil_the_era_of_blind_faith_in_big_data_must_end.

Acesso em: 07 abr. 2020.

PASCUAL, Manuel G. Quem vigia os algoritmos para que não sejam racistas ou sexistas? 17 mar. 2019. Disponível em: https://brasil.elpais.com/brasil/2019/03/18/tecnologia/1552863873_720561.html. Acesso em: 14 fev. 2020.

PUCPR. VOCÊ sabe o que faz o profissional de Big Data e Inteligência Analítica? 07 jun. 2018. Disponível em: encurtador.com.br/puzGV. Acesso em: 11 fev. 2020.

RAINIE, Lee; ANDERSON, Janna; ALBRIGHT, Jonathan. The Future of Free Speech, Trolls, Anonymity, and Fake News Online. Pew Research Center. March 29, 2017. Disponível https://pdfs.semanticscholar.org/a444/47ae039ead25900a844a4d900b88a01e63d8.pdf. Acesso em: 13 fev. 2020.

ROSAL, Fernanda R. Entendendo os algoritmos: propriedades e dilemas. In: TIC Domicílios 2017: pesquisa sobre o uso das tecnologias de informação e comunicação nos domicílios brasileiros. Núcleo de Informação e Coordenação do Ponto BR (Ed.) São Paulo: Comitê Gestor

Rev. de Direito, Inovação, Propriedade Intelectual e Concorrência | e-ISSN: 2526-0014 | Evento Virtual| v. 6 | n. 1 | p. 1-17 | Jan/Jun. 2020 
da Internet no Brasil, 2018. Disponível em: http://cetic.br/publicacoes/indice/pesquisas. Acesso em: 07 abr. 2020.

SALAS, Javier. Se está na cozinha, é uma mulher: como os algoritmos reforçam preconceitos. 232017.2 set. 23 Disponível https://brasil.elpais.com/brasil/2017/09/19/ciencia/1505818015_847097.html. Acesso em: 14 fev. 2020.

SAMPEDRO, Javier. Seu filho desenvolve o senso de justiça a partir dos quatro anos: Experimento sobre a psicologia da equidade revela diferenças nítidas entre sociedades. Disponível em: https://brasil.elpais.com/brasil/2015/11/18/ciencia/1447852141_256429.html. Acesso em: 14 fev. 2020.

SILVEIRA, Sergio Amadeu da. (2019). Democracia e os códigos invisíveis: como os algoritmos estão modulando comportamentos e escolhas políticas. Edições Sesc. Edição Kindle.

WARREN, Patricia Y.; FARRELL, Amy. (2009). The Environmental Context of Racial Profiling. Disponível em: https://doi.org/10.1177/0002716208330485. Acesso em: 10 abr. 2020.

WANG, Clarice et. al. (2020). A User Study on a De-Biased Career Recommender System. Disponível em: http://jfoulds.informationsystems.umbc.edu/papers/2020/Wang\%20(2020)\%20$\% 20 \mathrm{~A} \% 20 \mathrm{User} \% 20$ Study $\% 20$ on\%20a\%20De-

biased\%20Career\%20Recommender\%20System\%20(MASC-SLL_2020).pdf. Acesso em: 11 abr. 2020. 